\section{ECCOMAS}

\section{Proceedia}

COMPDYN 2021

$8^{\text {th }}$ ECCOMAS Thematic Conference on Computational Methods in Structural Dynamics and Earthquake Engineering M. Papadrakakis, M. Fragiadakis (eds.) Streamed from Athens, Greece, 28 - 30 June 2021

\title{
INFLUENCE OF PERPENDICULAR WALLS ON THE LATERAL STIFFNESS OF CLT SHEAR WALLS
}

\author{
E. Ruggeri ${ }^{1}$, G. D'Arenzo ${ }^{2}$, M. Fossetti ${ }^{3}$ and W. Seim ${ }^{4}$ \\ ${ }^{1}$ Faculty of Engineering and Architecture, Kore University of Enna, Italy \\ e-mail: elisabettamaria.ruggeri@unikorestudent.it \\ 2 Timber Engineering and Building Rehabilitation, University of Kassel, Germany \\ e-mail: giuseppe.darenzo@uni-kassel.de \\ ${ }^{3}$ Faculty of Engineering and Architecture, Kore University of Enna, Italy \\ e-mail: marinella.fossetti@unikore.it \\ 4 Timber Engineering and Building Rehabilitation, University of Kassel, Germany \\ e-mail: wseim@uni-kassel.de
}

\begin{abstract}
Cross-Laminated Timber (CLT) walls are used in CLT buildings to carry both vertical and horizontal loads. The mechanical behaviour of CLT shear walls for lateral loads is typically assumed to be governed from the base connections, which transfer the horizontal loads from the upper storeys to the foundations. However, in a CLT building, other connection typologies, such as the connection between shear walls and perpendicular walls, can contribute to the mechanical performances of the CLT shear walls. This paper presents a study on the effects of the perpendicular walls on the lateral stiffness of Cross-Laminated Timber shear walls. An analytical model for the calculation of the lateral stiffness of CLT shear walls connected at the base with typical hold-downs and angle brackets and to perpendicular walls by means of wall-to-wall connections is presented. The analytical model is compared with different models taken from the literature and validated against a numerical model developed in SAP2000. The analytical model is used to perform a parametric study in which the geometry and the connections are varied while different assumptions on the mechanical behaviour of the perpendicular walls are considered. Results of the parametric analyses showed that the perpendicular walls increase the lateral stiffness of CLT shear walls. The increase of lateral stiffness depends on the stiffness of the wall-to-wall connections, position and assumption on the behaviour of the perpendicular walls. Results of this study represent a basis for future studies in which the contribution of the perpendicular walls is investigated at building level.
\end{abstract}

Keywords: CLT shear walls, wall-to-wall connections, perpendicular walls interaction, mechanical models, parametric analyses

ISSN:2623-3347 C 2021 The Authors. Published by Eccomas Proceedia.

Peer-review under responsibility of the organizing committee of COMPDYN 2021.

doi:10.7712/120121.8640.19287 


\section{INTRODUCTION}

\subsection{Background}

The wooden structures sector has been growing strongly in recent decades due to a combination of different factors, such as the sustainability of the material, the fact that the structures are made of prefabricated elements which permit a fast erection of buildings and their good mechanical performances in case of seismic actions. In this context, Cross-Laminated Timber (CLT) structures play an important role that strongly contributes to the growth of the sector.

CLT structures are realized by means of CLT panels, which are mutually connected with metal fasteners and mechanical anchors. The Lateral Load Resisting System (LLRS) of this structural typology is composed of the CLT shear walls, which are connected to foundations by steel brackets, such as hold-downs and angle brackets, using small diameter fasteners like screws and nails. The CLT panels have a stiff behaviour if compared to that of the mechanical connections, therefore in a CLT building most of the structural flexibility is provided from the connections, which consequently play the most important role in terms of stiffness, strength and ductility of the structure.

The seismic performance of CLT structures has been the central topic of several experimental research projects that were carried out on wall systems and full-scale buildings. In Europe several experimental campaigns were performed to investigate the seismic behaviour of CLT shear walls, see for instance [1-3]. The results of these studies showed that the layout of connections influence the cyclic behaviour of shear walls and that the CLT panels act as rigid bodies with low in-plane deformations. One of the largest experimental research activities on the seismic behaviour of low-and-medium-rise CLT buildings was carried out within the SOFIE Project [4], in which shake table tests on a three- and a seven-story CLT building were performed. The outcomes of tests on the buildings showed that the CLT panels remained undamaged and failures were observed only locally in joints and connections.

In CLT buildings, the lateral deformation mechanisms of the shear walls are considered when determining their lateral stiffness and resistance. CLT shear walls subjected to lateral loads typically deform with a combined mechanism of rocking and sliding. Regarding the lateral resistance, a global failure mechanism related to rocking behaviour is typically observed in CLT shear walls with a low width-to-height aspect ratios, while sliding failures occur in CLT shear walls with high width-to-height aspect ratios [3,5]. Regarding the lateral stiffness, several analytical models are available in literature to calculate the shear wall lateral stiffness and some of these analytical studies are discussed in the next sections.

Knowing the lateral stiffness of CLT shear walls is important for determining the distribution of the lateral loads among the shear walls of CLT buildings. If a rigid behaviour can be assumed for the floor diaphragms, the distribution of the lateral loads among the shear walls can be assumed - in elastic analyses - proportional to their lateral stiffness. The load undertaken from each shear wall can be then used for designing the wall base connections, unless capacity design strategies are adopted. The overall lateral stiffness and capacity of the CLT building is therefore calculated as the sum of the capacities of the individual shear walls, which work as an in-parallel system.

However, the lateral stiffness of CLT shear walls can be influenced from other connections typologies that are present in CLT buildings, such as the connections between the shear walls and perpendicular walls, see Fig.1. Such connections can contribute to variate the lateral stiffness of CLT shear walls and contribute mostly to the so-called box-behaviour of the CLT buildings. 


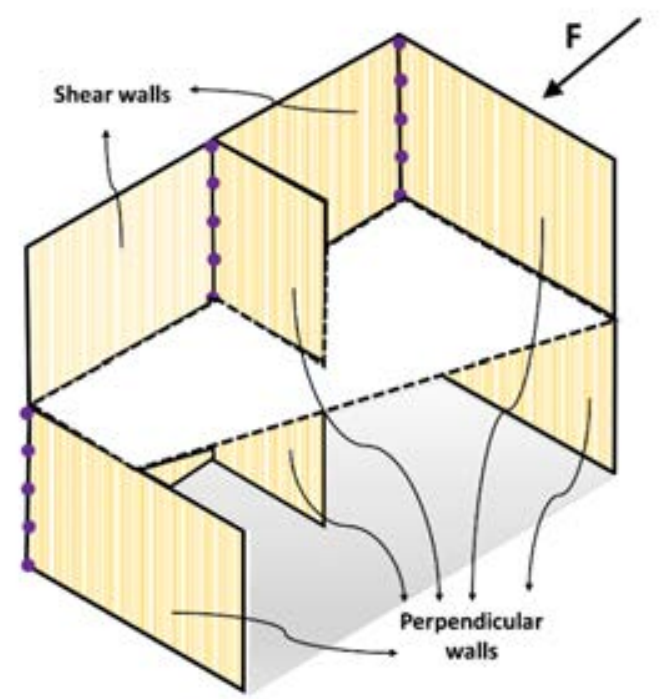

Fig.1: Representation of a typical CLT building with shear and perpendicular walls.

\subsection{Effect of perpendicular walls}

The behaviour of shear walls can be influenced from the three-dimensional behaviour of the building. In this respect, the perpendicular walls and the connections to the shear walls can play an important role. However, the research on the effects of perpendicular walls on seismic performance of CLT shear walls is limited.

The effects of perpendicular walls was found in several experimental campaigns on full-size Light Frame Timber (LFT) platform buildings [6, 7]. Such effects were found also from Popovski and Gavric [8], who investigated the three-dimensional performance of a two-story CLT building under lateral cyclic loads. In this experimental study, uplift of the perpendicular walls, which contributed to the overall building capacity, were detected. Such result highlighted that perpendicular walls may act as a hold-down system and have a significant effect on the lateral-load resistance and deformability of CLT structures. In a subsequent study [9] the same authors calculated the building lateral capacity and found an additional contribution to the lateral resistance given from the perpendicular walls. In the study, the authors concluded that the influence of perpendicular walls shall be included in the analytical design of CLT shear walls.

The influence of the perpendicular walls on the lateral stiffness and capacity of CLT buildings was found also in analytical and numerical studies.

Shahnewaz et al.[10], presented closed-form equations to estimate the deflection of single and coupled CLT shear walls under lateral loading considering the influence of wall-to-wall and floor-to-wall connections. Parametric analyses showed that the presence of perpendicular wall reduces the deflections as a function of the stiffness of the connections.

Hummel et al. [11] considered the influence of the perpendicular walls in seismic analyses of CLT buildings, to evaluate the q-factor. From this study, it is emerged that connecting shear walls to perpendicular walls provides an increase of the lateral resistance and of the deformation capacity of the building.

Tamagnone et al. [12], proposed a simplified non-linear procedure for seismic design of CLT wall systems that was validated against two- and tree-dimensional numerical models. While acceptable accuracy was obtained in the comparison with two-dimensional numerical models, larger errors were detected in comparisons with three-dimensional models due to the box effect of the CLT building provided from the connection between perpendicular walls. In this study, 
the authors concluded that the box behaviour has a stiffening influence on the response of shear walls, which decreases the sliding and rocking deformations of the shear walls.

Typically, in the practical design, the influence of the perpendicular walls on the mechanical behaviour of CLT buildings is not taken into account. Although this approach simplifies the seismic design procedure, from the other side it neglects the effects of the perpendicular walls and the box behaviour of the building, which was found in several studies to be significative.

With the aim to quantify these effects, this paper proposes an analytical model for the evaluation of the elastic horizontal stiffness of CLT shear walls connected to perpendicular walls through wall-to-wall connections.

\section{HORIZONTAL STIFFNESS OF CLT SHEAR WALLS}

\subsection{Analytical models from the literature}

Analytical models for the design of CLT shear walls are based on the different contributions of the shear wall deformations.

The evaluation of lateral stiffness of CLT shear walls is carried out with analytical models that consider the kinematic behaviour of the wall. Typically, three displacement contributions take place in CLT shear walls under lateral loads: rigid-body rotation (rocking), rigid-body translation (sliding), and panel deformation which has a shear and a bending contribution, see Fig.2.

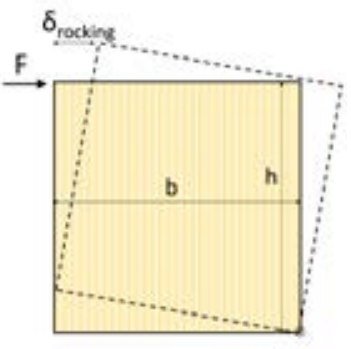

(a)

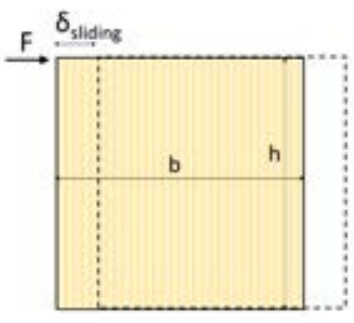

(b)

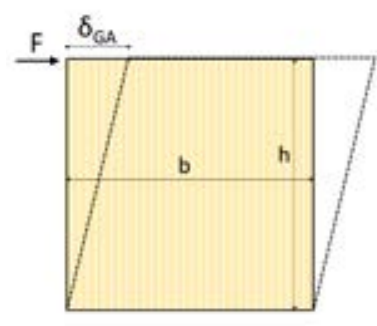

(c)

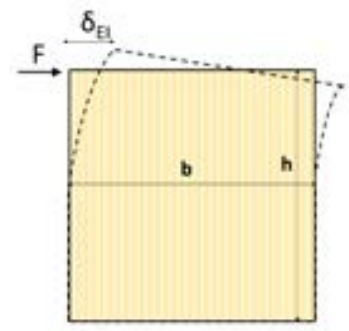

(d)

Fig. 2: CLT shearwall deformation mechanisms: rocking (a), sliding (b), in plane shear deformation (c), in plane bending deformation (d).

The total displacement of CLT shear wall, $\delta_{\text {wall }}$, subject to a horizontal force F, can be written as shown in equation Eq.(1):

$$
\delta_{\text {wall }}=\delta_{\text {rocking }}+\delta_{\text {sliding }}+\delta_{G A}+\delta_{E I}
$$

Eq.(1) is valid for a single CLT shear wall, while in the case of multi-storey shear wall assemblies the contribution of the cumulated rotation should be also taken into account.

Several models for calculating the horizontal displacement of a CLT shear wall, which are based on different assumptions regarding the deformation mechanisms, are available in literature, see for instance $[3,5,13-15]$. In the next, three of these models are discussed to report a short state-of-the-art. The models are reported by considering the effect of the lateral loads and neglecting the contribution of the vertical loads, as not of interest for the scope of this work.

\subsubsection{Casagrande et al. [5]}

Casagrande et al. [5] presented a simplified analytical method to evaluate the horizontal displacement of a CLT shear wall. Three deformation mechanisms are considered: rigid-body rotation, rigid-body translation and in plane shear panel deformation. In this model, the bending deformation of panel is neglected. 
The contribution of rocking deformation depends on the stiffness of the hold-down and on the wall geometry, according to Eq.(2):

$$
\delta_{\text {rocking }}=\left(\frac{F h^{2}}{K_{H D}(\tau b)^{2}}\right)
$$

In which:

$F$ is the horizontal force,

$h$ is height of the CLT shear wall,

$(\tau b)$ is the distance of hold-down from the point of rotation of the CLT panel,

$K_{H D}$ is the stiffness of the hold-down

The horizontal sliding contribution depends on the angle bracket's stiffness, see Eq.(3):

$$
\delta_{\text {sliding }}=\frac{F}{n_{A B} k_{A B}}
$$

In which:

$n_{A B}$ is the number of angle brackets,

$k_{A B}$ is the stiffness of one angle bracket.

The shear panel deformation depends on the geometry and the shear modulus of the CLT panel, see Eq.(4):

$$
\delta_{G A}=\frac{F h}{G_{C L T} A_{e f f}}
$$

In which:

$G_{C L T}$ and $A_{\text {eff }}$ are the shear modulus and the effective shear area of the CLT panel.

\subsubsection{Hummel et al. [13]}

Hummel et al. [13] proposed a method that takes into account the four deformation contributions shown in Fig.2.

Two cases are considered for the rocking deformation: a rigid foundation (for instance, concrete foundation) and an elastic foundation (for instance, CLT floor). While in case of rigid foundation, the rocking contribution is the same of Eq.(2), in case of elastic foundation, the rocking contribution is given in Eq.(5):

$$
\delta_{\text {rocking }}=\frac{h^{2}}{l^{*}-\frac{l_{c}}{3}} \cdot \frac{2 F}{K_{D} l_{c}^{2}}
$$

In which $K_{D}$ is the stiffness of elastic foundation and $l^{*}$ is the distance between the centre of rotation of the wall and the furthest hold-down and $l_{c}$ is the length of zone in compression. The stiffness of elastic foundation can be calculated as $K_{D}=\frac{E_{s} b_{s}}{t_{s}}$, where $b_{s}$ and $t_{s}$ define the wall width and thickness, respectively, and $E_{s}$ is the modulus of elasticity of the elastic foundation.

The contributions due to sliding and shear deformation can be calculated with Eq.(3) and (4) respectively.

The contribution due to the bending deformation can be calculated with Eq.(6):

$$
\delta_{E I}=\frac{F h^{3}}{3 E_{C L T} I_{e f f}}
$$

In which:

$E_{C L T}$ and $I_{\text {eff }}$ are the elastic modulus and the effective inertia of the CLT panel. 


\subsubsection{Gavric et al. [3]}

The model proposed from Gavric et al. [3] takes into account the whole load-displacement curve of the connectors and it is able to predict the entire elasto-plastic behaviour of the shear wall, by means of a step-by-step analysis. In this paper, only the part related to elastic displacements is presented. The difference between the model proposed from Gavric et al. [3] and the previous two models regards the behaviour of angle brackets for tensile loads. The analytical model from Gavric et al. [3] assumes that all wall base connections react with vertical tensile loads.

This model considers the four shear wall deformation contributions given in Fig.2. The lateral displacement due to rigid-body rotation is given by the rotational equilibrium considering the tensile force in the generic connection. The contribution of rocking deformation can be calculated with Eq.(7)

$$
\delta_{\text {rocking }}=\left(\frac{F h^{2}}{\sum_{i=1}^{n} K_{i} x_{i}^{2}}\right)
$$

In which:

$K_{i}$ and $x_{i}$ are the vertical stiffness and the distances from the point of rotation of the CLT panel of the $i^{\text {th }}$ wall base connection.

The contributions due to sliding, shear and bending panel deformations can be calculated with Eq.(3), (4) and (6), respectively.

\subsection{CLT shear walls connected to perpendicular walls}

In the next, an analytical model of laterally loaded CLT that considers the contribution of the wall base connections and the contribution of the connection between the shear wall and the perpendicular wall is presented. The model is defined with the aim to quantify the additional contribution of the connection between the shear wall and the perpendicular wall on the lateral stiffness of the shear wall.

The model, shown in Fig.3, is based on the following assumptions: only the wall-base connections and the wall-to-wall connections between the shear wall and perpendicular wall are considered. The monodirectional behaviour of the wall base connection is considered, therefore hold-downs are modelled as vertical elastic springs whereas angle brackets as horizontal elastic springs. It is assumed that the CLT walls behave as rigid bodies, hence the deformations due to CLT panels are not taken into account.

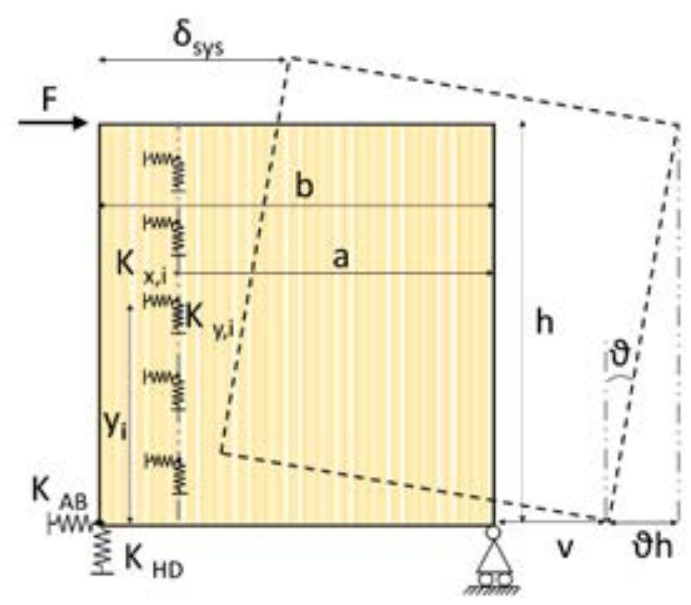

Fig. 3: Mechanical system of CLT shear wall connected to a perpendicular wall. 
Consider the kinematic variables of the mechanical system shown in Fig.3, $v$ and $\vartheta$, whose meaning is given in Fig.3 and the substitutions shown in Eq.8.

$$
\begin{gathered}
\delta_{\text {rocking }}=\vartheta h \\
\delta_{\text {sliding }}=v \\
\delta_{\text {sys }}=\vartheta h+v
\end{gathered}
$$

The total potential energy principle is used for defining the equilibrium equations of the system shown in Fig.3, with the aim to define the horizontal displacement of the model as function of the stiffness of the connections. The total potential energy of the mechanical system can be evaluated as the difference between the elastic energy of the system and the energy associated to the external horizontal force, see Eq.(10).

$$
E_{\text {tot }}=\frac{1}{2} K_{A B} v^{2}+\frac{1}{2} K_{H D}(\vartheta b)^{2}+\frac{1}{2} \sum_{i=1}^{n_{w-w}} K_{x}\left(v+\vartheta y_{i}\right)^{2}+\frac{1}{2} n_{w-w} K_{y}(\vartheta a)^{2}-F(v+\vartheta h)
$$

In which $K_{A B}$ represents the sum of the horizontal stiffness of the angle brackets, $K_{H D}$ represents the vertical stiffness of the hold-down, $\mathrm{K}_{x}$ and $\mathrm{K}_{y}$ are the stiffness of the wall-to-wall connections in the horizontal and vertical direction, respectively, and $n_{w-w}$ is the number of wallto-wall connections.

According to the total potential energy principle, the equilibrium condition of the mechanical system shown in Fig. 3 can be found by equating the first derivative of the total potential energy respect to the kinematic variables of the system to zero.

$$
\begin{aligned}
& \frac{\partial E_{t o t}}{\partial v}=K_{A B} v+n_{w-w} K_{x} v+K_{x} \sum_{i=1}^{n_{w-w}} y_{i} \vartheta+F=0 \\
& \frac{\partial E_{t o t}}{\partial \vartheta}=K_{H D} b^{2} \vartheta+K_{x} \sum_{i=1}^{n_{w-w}} y_{i}^{2} \vartheta+K_{x} \sum_{i=1}^{n_{w-w}} y_{i} v+n_{w-w} K_{y} a^{2} \vartheta+F h=0
\end{aligned}
$$

Eq.(11) and Eq.(12) represent the system of two equations, one of translational equilibrium and one of rotational equilibrium, which describe the analytical model shown in Fig.3.

$$
\left\{\begin{array}{c}
F=\left(K_{A B}+n_{w-w} K_{x}\right) v+\left(K_{x} \sum_{i=1}^{n_{w-w}} y_{i}\right) \vartheta \\
F h=\left(K_{x} \sum_{i=1}^{n_{w-w}} y_{i}\right) v+\left(K_{H D} b^{2}+K_{x} \sum_{i=1}^{n_{w-w}} y_{i}^{2}+n_{w-w} K_{y} a^{2}\right) \vartheta
\end{array}\right.
$$

\subsection{Comparison of elastic stiffness matrix}

The different wall displacement contributions described in the previous sections represent equilibrium equations of different elastic systems. On this basis, the displacement contributions of the CLT wall system can be written in the form shown in Eq.(14).

$$
\{\boldsymbol{F}\}=[\boldsymbol{K}] \cdot\{\boldsymbol{\delta}\}
$$

In which $\boldsymbol{F}$ is the vector of the forces, $\boldsymbol{K}$ is the elastic stiffness matrix of the system and $\boldsymbol{\delta}$ is the vector of the displacements. 
The analytical model of Casagrande et al. [5], described in section 2.1.1, can be written as shown in Eq.(15).

$$
\left\{\begin{array}{c}
F \\
F h
\end{array}\right\}=\left[\begin{array}{cc}
n_{A B} k_{A B} & 0 \\
0 & K_{H D} \tau^{2} b^{2}
\end{array}\right]\left\{\begin{array}{l}
v \\
\vartheta
\end{array}\right\}
$$

The analytical model of Hummel et al. [13] can be written as in Eq.(15) in case of rigid foundation, whereas in case of elastic foundation can be written as shown in Eq.(16).

$$
\left\{\begin{array}{c}
F \\
F h
\end{array}\right\}=\left[\begin{array}{cc}
n_{A B} k_{A B} & 0 \\
0 & \frac{1}{2} K_{D} l_{C}^{2}\left(l^{*}-\frac{l_{C}}{3}\right)
\end{array}\right]\left\{\begin{array}{l}
v \\
\vartheta
\end{array}\right\}
$$

The analytical model of Gavric et al. [3], described in section 2.1.3, can be written as shown in Eq.(17).

$$
\left\{\begin{array}{c}
F \\
F h
\end{array}\right\}=\left[\begin{array}{cc}
n_{A B} k_{A B} & 0 \\
0 & \sum_{i=1}^{n} K_{i} x_{i}^{2}
\end{array}\right]\left\{\begin{array}{l}
v \\
\vartheta
\end{array}\right\}
$$

The analytical model presented in this work, described at the Section 2.2, can be written as shown in Eq.(18).

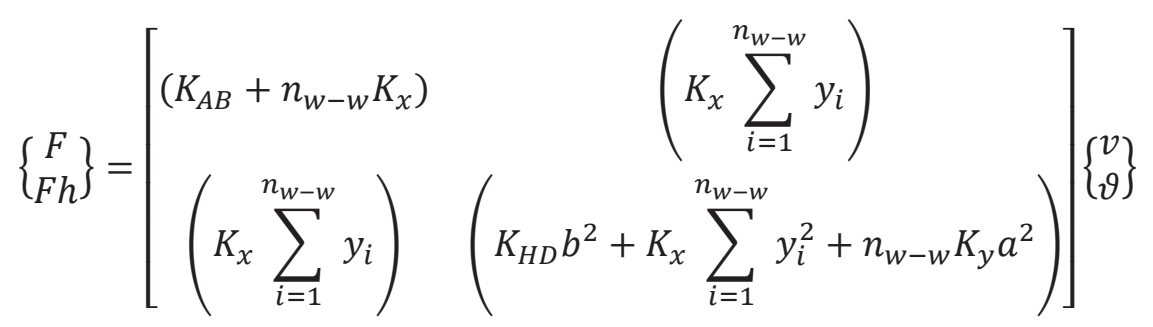

It is possible to observe that, the equations (15) to (17) describe diagonal matrices, in which sliding and rocking of a single shear wall are independent. In these cases, the stiffness of rocking ( $\left.\mathrm{K}_{\text {rocking }}\right)$ and the stiffness of sliding $\left(\mathrm{K}_{\text {sliding }}\right)$ depend on terms in the diagonal of the stiffness matrix.

The new model of shear wall with wall-to-wall connections given in Eq.(18) describes an elastic stiffness matrix in which sliding and rocking are mutually influenced. Shear wall connected to perpendicular wall model constitute a system, which is statically indeterminate, differently from the shear wall models without wall-to-wall connections between perpendicular walls.

From the resolution of the system described with Eq.(18), it is possible to obtain the horizontal contribution of deformation due to rocking ( $\left.\delta_{\text {rocking }}\right)$, see Eq.8(a), and sliding $\left(\delta_{\text {sliding }}\right)$, see Eq.8(b), which depend on the stiffness of hold-down, angle brackets and wall-to-wall connections. As consequence, the rocking stiffness ( $\left.\mathrm{K}_{\text {rocking }}\right)$ and the sliding stiffness $\left(\mathrm{K}_{\text {sliding }}\right)$ of the system depend on hold-down, angle brackets and wall-to-wall connections, and can be calculated with Eq.19(a) and (b).

$$
\begin{gathered}
K_{\text {rocking }}=\frac{F}{\delta_{\text {rocking }}} \\
K_{\text {sliding }}=\frac{F}{\delta_{\text {sliding }}}
\end{gathered}
$$

Since the CLT walls deform under lateral load as an in-series system, the overall stiffness of the system can be calculated with Eq.(20). According to Casagrande et al. [5], Eq.(20) can 
schematized as shown in Figure 4(a) in the case of shear wall without the wall-to-wall connections. Considering the effect of the wall-to-wall connections the system can be modified as shown in Figure 4(b), from which is possible to observe that the sliding and rocking stiffness continue to work as in-series system. However in this case, the mutual influence of the connections system contribute to increase their magnitude working as an internal in-parallel system.

$$
K_{\text {sys }}=\left(\frac{1}{K_{\text {rocking }}}+\frac{1}{K_{\text {sliding }}}\right)^{-1}
$$

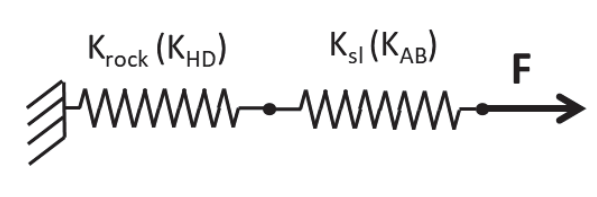

(a)

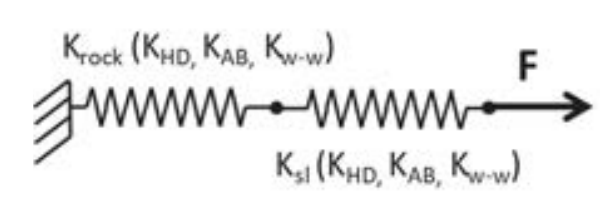

(b)

Fig. 4: Scheme of two elastic in-series springs for single shear wall (a) and for shear wall connected to perpendicular wall (b).

The horizontal elastic displacement of the CLT shear wall can be calculated as function of the overall stiffness of the system as shown in Eq.(21):

$$
\delta_{s y s}=\frac{F}{K_{s y s}}
$$

\section{NUMERICAL MODEL}

To validate the correctness of the analytical model presented in the previous section, an analogous numerical model of CLT shear wall anchored with wall base and wall-to-wall connections is presented in this section. The numerical model, developed in the FE software SAP2000 [16], is a two-dimensional model composed of shell elements and elastic springs, see Fig.5.

To simulate the assumption of wall panel rigid behaviour, the CLT panel was modelled as isotropic shell element from SAP2000 library with a high elastic modulus equal to 200.000 MPa. Analogously to the analytical model, hold-downs and angle brackets were considered effective along their primary direction. Hold-downs were modelled as 1-joint vertical elastic springs connected to the tense side of the wall end. Angle brackets were modelled as a unique lumped 1-joint horizontal elastic springs connected to the wall end. The compressed corner of the CLT shear wall was modelled with a vertical support that allowed horizontal translation and rotation. The wall-to-wall connections were modelled with a series of 1-joint elastic springs acting in the vertical and horizontal direction, $\mathrm{z}$ and $\mathrm{x}$ according to Fig.5. 


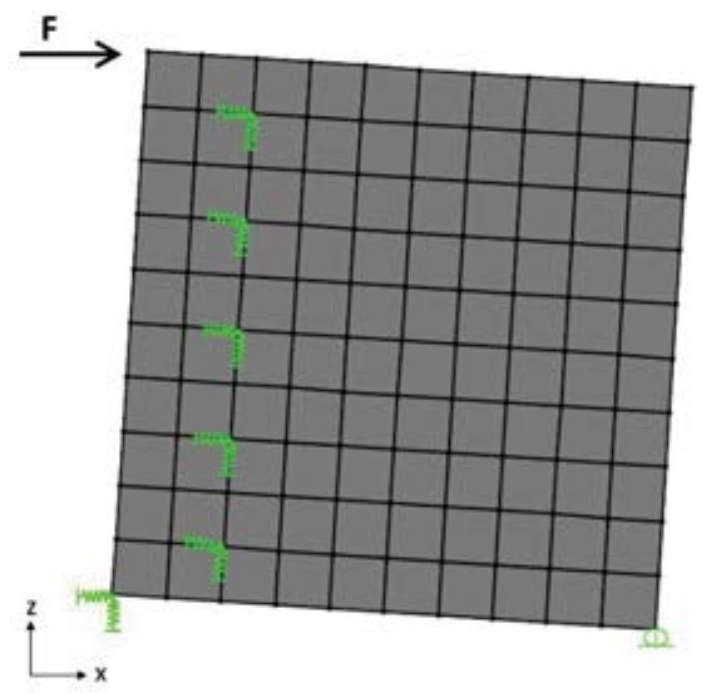

Fig. 5: FEM model of CLT shear wall and connections.

The values of stiffness of the elastic springs representing the different CLT connections were taken from experimental campaigns from the literature. Such values and the wall geometries are given in the next section, in which a parametric analysis is presented with the aim to check the correctness of the analytical model and to investigate the stiffening effect of the wall-towall connections in different geometrical and mechanical conditions.

\section{PARAMETRIC ANALYSIS}

The analytical model presented in section 2.2 and the numerical model presented in the previous sections are used in this chapter to perform a parametric analysis in which different geometrical and mechanical properties of CLT walls are considered.

Since the lateral behaviour of a CLT shear wall strongly depends on the wall aspect ratio three different wall aspect ratio equal to $\mathrm{b} / \mathrm{h}=0.5, \mathrm{~b} / \mathrm{h}=1.0$ and $\mathrm{b} / \mathrm{h}=1.5$ were analysed in the parametric analysis, see Fig.6.

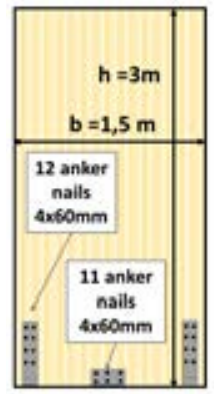

(a)

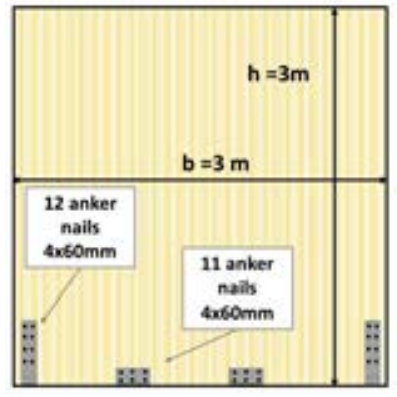

(b)

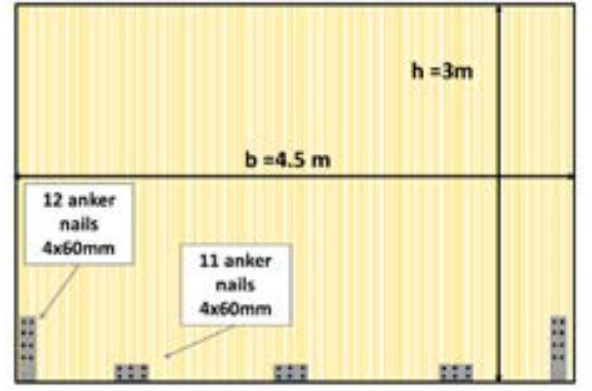

(c)

Fig. 6: Aspect ratio of the shear walls: $b / h=0.5(a), b / h=1$ (b) and $b / h=1.5$ (c).

The parametric analysis was carried out by considering mechanical properties of wall base connections based on experimental results from Gavric et al. [3]. In this study, hold-downs with twelve $4 \times 60 \mathrm{~mm}$ nails, and angle brackets with eleven $4 \times 60 \mathrm{~mm}$ nails were tested under tension and shear loads, respectively. Based on these experimental results, the values of stiffness of hold-downs and one angle bracket used in the parametric analysis were set equal to $4.59 \mathrm{kN} / \mathrm{mm}$ and $1.96 \mathrm{kN} / \mathrm{mm}$, respectively. As shown in Fig.6, one, two and three angle brackets were considered for the three different wall aspect ratios $\mathrm{b} / \mathrm{h}=0.5, \mathrm{~b} / \mathrm{h}=1.0$ and $\mathrm{b} / \mathrm{h}=1.5$, respectively. 
The stiffness of the wall-to-wall connections was assigned based on experimental results from [17], in which wall-to-wall connections between perpendicular walls with self-tapping screws $10 \times 180 \mathrm{~mm}$, installed with an inclination of $90^{\circ}$ respect to the plane of the shear wall, were tested. A stiffness equal to $1.53 \mathrm{kN} / \mathrm{mm}$ was considered for the wall-to-wall connections in both vertical and horizontal direction. The spacing between each connection was set equal to $300 \mathrm{~mm}$ that for a wall height of $3 \mathrm{~m}$ led to a number of wall-to-wall connections equal to $\mathrm{n}_{\mathrm{w}-}$ ${ }_{\mathrm{w}}=10$.

As shown in Fig.1, perpendicular walls can be connected to shear walls in different positions.

Such positions can differently influence the mechanical behaviour of the shear wall. To evaluate such aspect, three different position of the wall-to-wall connections were considered in this study, as shown in Fig.7:

$i$. Perpendicular wall on tense side of the shear wall,

ii. Perpendicular wall on central side of the shear wall,

iii. $\quad$ Perpendicular wall on compressed side of the shear wall.

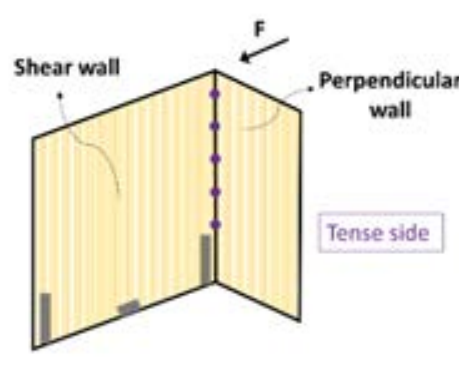

(i)

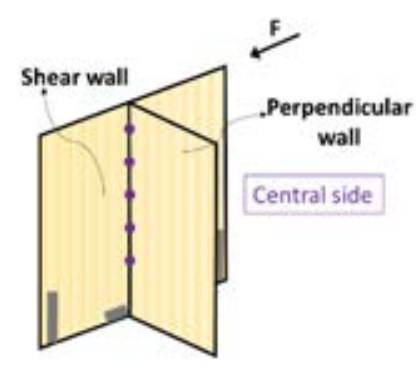

(ii)

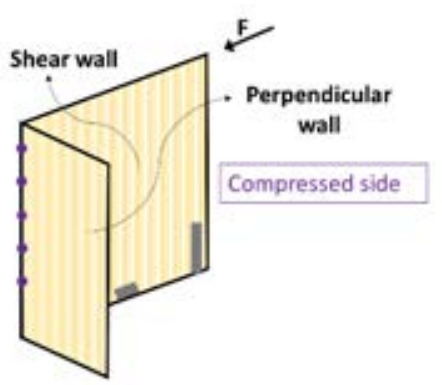

(iii)

Fig. 7: Position of perpendicular wall respect to shear wall: tense side (i), central side (ii) and compressed side (iii).

It should be mentioned that the stiffening contribution of the perpendicular walls on the lateral stiffness of the shear wall depends on the wall-to-wall connections as well as on the stiffness of the wall base connections of the perpendicular wall. From Fig.8(a), it is possible to observe that the rocking mechanism of the shear wall is influenced from the vertical stiffness of the wall-to-wall connections and on the vertical stiffness of the hold-downs of the perpendicular wall. On the other hand, the sliding mechanism is differently influenced from the perpendicular walls, which cannot undertake the horizontal load of the wall-to-wall connections since their wall base connections mostly have a hinge behaviour in the direction out of the plane, which do not permit the transfer of such forces, see Fig.8(b). To investigate such aspects, the parametric analysis was performed in three different conditions:

iv. Both vertical and horizontal stiffness considered with $\mathrm{K}_{\mathrm{y}}=\mathrm{K}_{\mathrm{x}}=1.53 \mathrm{kN} / \mathrm{mm}$;

v. Only the vertical stiffness considered with $\mathrm{K}_{\mathrm{y}}=1.53 \mathrm{kN} / \mathrm{mm}$ and $\mathrm{K}_{\mathrm{x}}=0$;

vi. Only the vertical stiffness considered with $\mathrm{K}_{\mathrm{y}}=0.35 \mathrm{kN} / \mathrm{mm}$ and $\mathrm{K}_{\mathrm{x}}=0$;

While the condition $i v$ is representative of the potential condition in which the lateral load can be transfer to the perpendicular wall by means of both rocking and sliding mechanism, the conditions $v$ and $v i$ represent the realistic conditions in which only the rocking mechanism contributes to transfer the lateral load to the perpendicular walls. The condition $v$ represents the case of perpendicular wall connected at the base with highly rigid hold-downs whereas in the condition vi represents the case of perpendicular wall connected at the base with flexible hold- 
downs. In the case $v i$ the stiffness $\mathrm{K}_{\mathrm{y}}$ is calculated assuming an in-series behaviour of wall-towall connections and hold-down of the perpendicular wall.

The parameters used for the parametric analyses are summarized in Table 1.

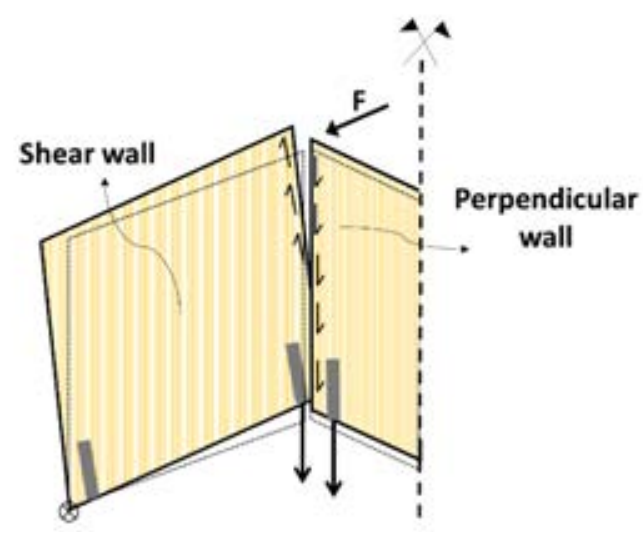

(a)

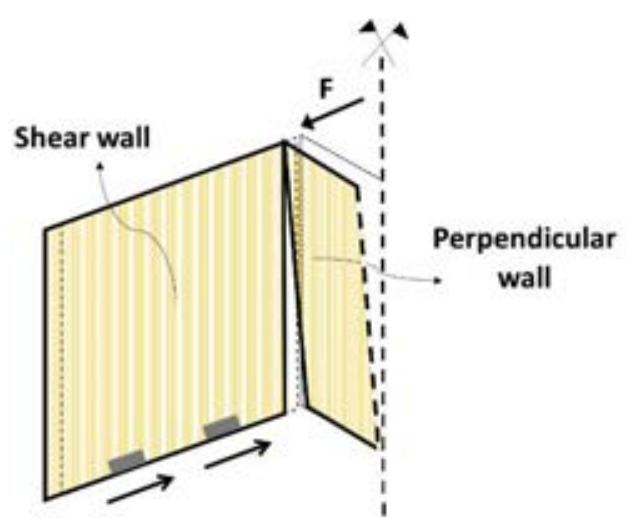

(b)

Fig. 8: Rocking (a) and sliding (b) mechanism of shear wall connected to perpendicular wall.

\begin{tabular}{|c|c|c|c|c|c|c|c|}
\hline $\begin{array}{l}\text { Perp. wall } \\
\text { Position }\end{array}$ & $\begin{array}{c}\mathrm{h} \\
{[\mathrm{m}]}\end{array}$ & $\begin{array}{l}\mathrm{h} / \mathrm{b} \\
{[-]}\end{array}$ & $\begin{array}{c}\mathrm{K}_{\mathrm{HD}} \\
{[\mathrm{kN} / \mathrm{mm}]}\end{array}$ & $\begin{array}{c}\mathrm{K}_{\mathrm{AB}} \\
{[\mathrm{kN} / \mathrm{mm}]}\end{array}$ & $\begin{array}{c}\mathrm{K}_{\mathrm{y}} \\
{[\mathrm{kN} / \mathrm{mm}]}\end{array}$ & $\begin{array}{c}\mathrm{K}_{\mathrm{x}} \\
{[\mathrm{kN} / \mathrm{mm}]}\end{array}$ & $\begin{array}{c}\mathrm{n}_{\mathrm{W}-\mathrm{w}} \\
{[-]}\end{array}$ \\
\hline Tense side & \multirow{3}{*}{3} & 0.5 & \multirow{3}{*}{4.59} & 1.96 & $1.53^{(i v, v)}$ & $1.53^{(i v)}$ & \multirow{3}{*}{10} \\
\hline Central side & & 1.0 & & 3.92 & $0.35^{(v i)}$ & $0^{(v, v i)}$ & \\
\hline $\begin{array}{l}\text { Compressed } \\
\text { side }\end{array}$ & & 1.5 & & 5.88 & & & \\
\hline
\end{tabular}

Tab. 1: Parameters used for the parametric analyses.

\section{RESULTS AND DISCUSSION}

To evaluate the influence of the wall-to-wall connection on the lateral stiffness of the shear walls, the parametric analysis was carried out considering the conditions given in Table 1 and the benchmark condition in which the wall-to-wall connections are not considered. Such analyses were performed by using the equations of the analytical model given in Section 2.2 and the numerical model presented in Section 3. Results in terms of wall stiffness from the analytical and numerical models showed differences smaller than $1 \%$ for all the conditions analysed.

The results of parametric analysis are reported in Fig.9, Fig.10 and Fig.11, for the cases $i v$, $v$ and $v i$ described in the previous section, respectively. The figures show graphs organized in matrix form representing the different wall aspect ratios and perpendicular wall positions. Each graph reports the lateral stiffness and the rocking and sliding displacement contributions of the shear wall. The rocking and sliding displacement contributions were calculated as the ratio between the rocking and sliding displacement, calculated from Eq.8(a) and (b), and the total displacement, calculated from Eq.9. 


\section{E. Ruggeri, G. D’Arenzo, M. Fossetti and W. Seim}

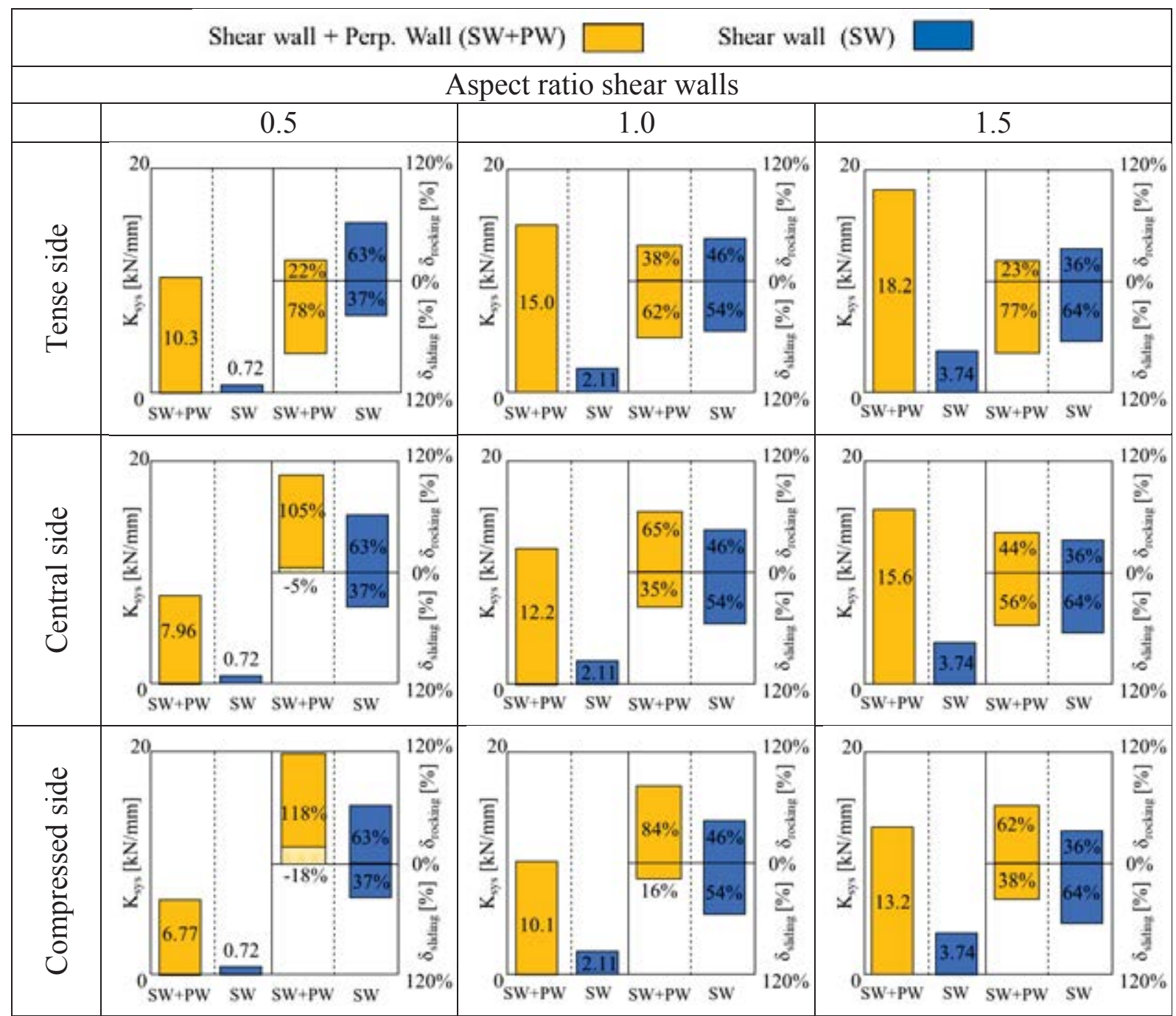

Fig. 9: Results of parametric analysis for the case $i v$.

It is possible to observe that there is an increase of the lateral stiffness in all cases analysed, due to the effect of the wall-to-wall connections. Such effect is always larger in the case of the perpendicular wall is anchored to the tense side of the shear wall and reduces as the perpendicular wall is moved toward the compressed side of the shear wall. The highest increases of stiffness are observed for wall aspect ratios equal to $\mathrm{b} / \mathrm{h}=0.5$ and such stiffening effect decreases as the wall aspect ratio $\mathrm{b} / \mathrm{h}$ increases.

In the case $i v$, in which the shear walls can potentially transfer both uplift and lateral forces to the perpendicular walls, the highest increases of stiffness are observed. In this case, increases of the lateral stiffness up to 14 times respect to the case without the wall-to-wall connections can be observed. The results in terms of increase of lateral stiffness of the case $i v$ show the potential effect of the wall-to-wall connections on the stiffness of the shear wall. 


\section{E. Ruggeri, G. D’Arenzo, M. Fossetti and W. Seim}

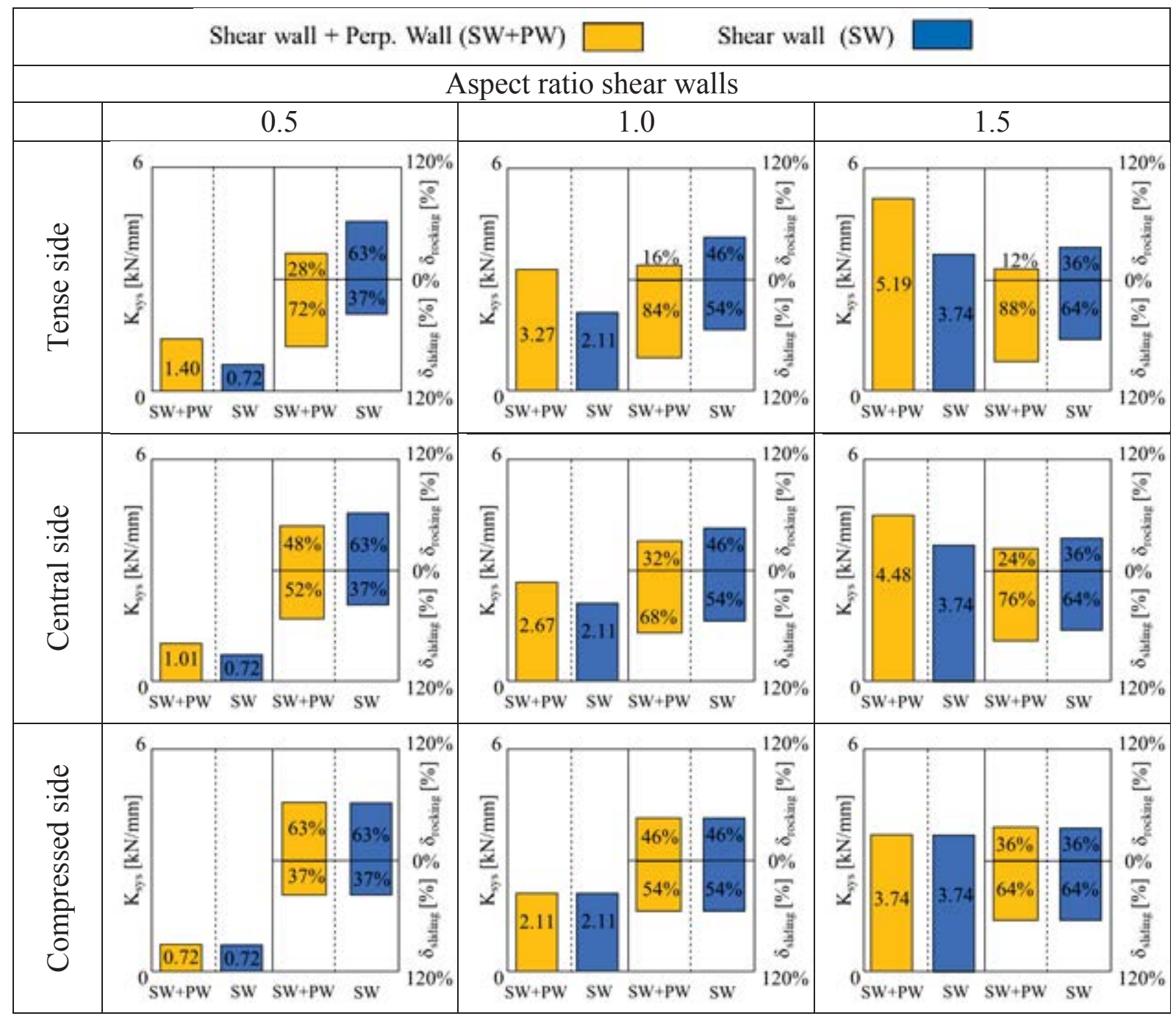

Fig. 10: Results of parametric analysis for the case $v$.

In the case $v$, in which the shear walls transfer only uplift forces to the perpendicular walls and the latter are anchored with stiff hold-downs, great reductions of the increase of lateral stiffness in comparison to the case $i v$ are observed. In this case, increases of the lateral stiffness up to 2 times respect to the case without the wall-to-wall connections can be observed. Such result is due to the absence of the stiffening contribution for the sliding mechanism, which consequently become the predominant deformation mechanism. Such aspect can be observed also from the deformation mechanism contributions: in the cases where there are the highest increases of lateral stiffness there are also the greatest change in the deformation mechanisms of the shear wall.

In the case $v i$, in which the shear walls transfer only uplift forces to the perpendicular walls and the latter are anchored with flexible hold-downs, further reductions of the increase of lateral stiffness in comparison to the case $v$ are observed. In this case, increases of the lateral stiffness up to 1.4 times respect to the case without the wall-to-wall connections can be observed.

In both cases $v$ and $v i$, it is interesting to note the when the perpendicular wall is placed on the compressed side of the shear wall, none increase of stiffness is detected. 


\section{E. Ruggeri, G. D’Arenzo, M. Fossetti and W. Seim}

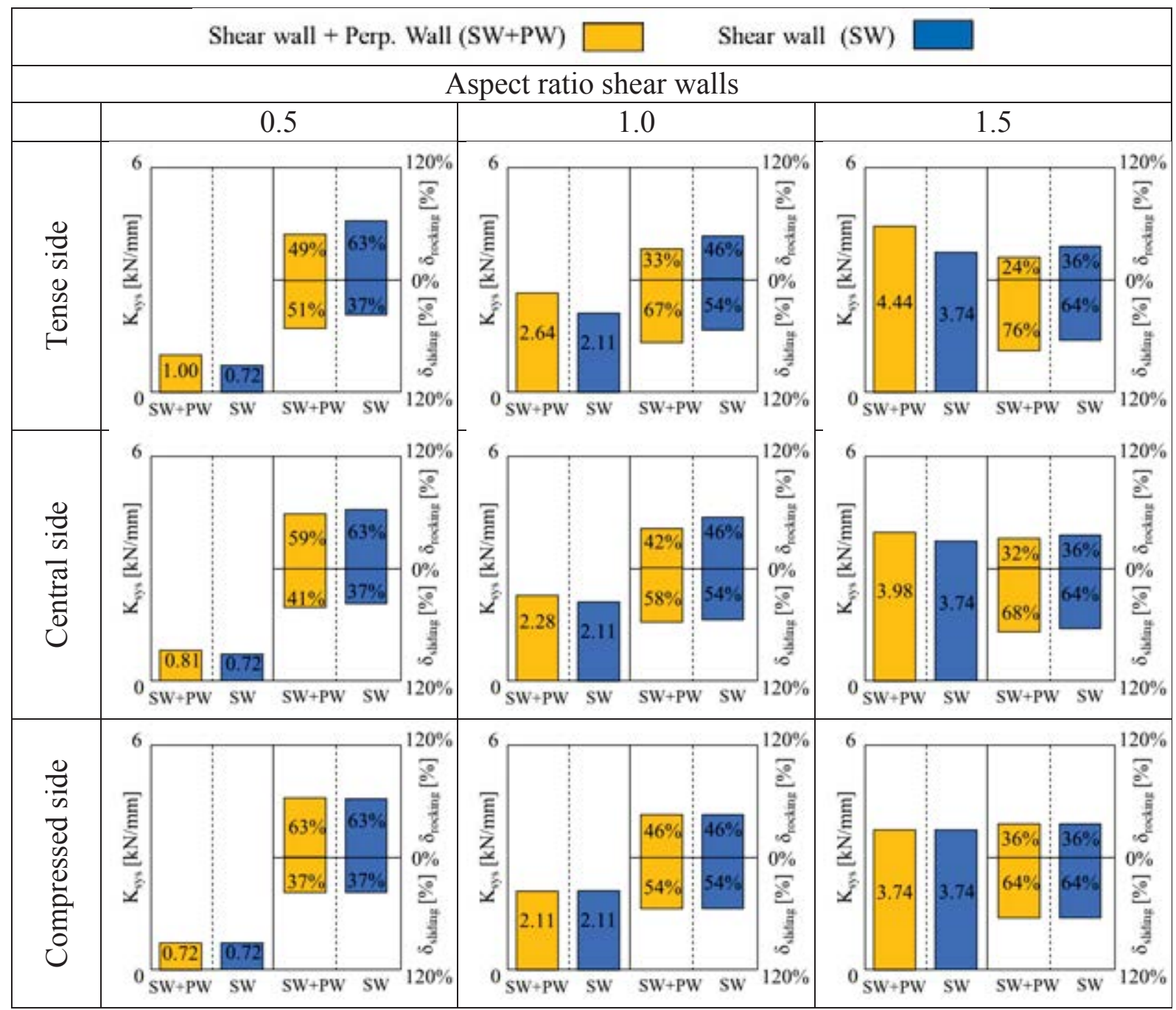

Fig. 11: Results of parametric analysis for the case vi.

\section{CONCLUSIONS}

In this paper, a study on the effect of the perpendicular walls on the lateral stiffness of CLT shear walls is presented. A new analytical model capable of calculating the stiffness of CLT shear walls connected to perpendicular walls through wall-to-wall connections is presented. The new analytical model is compared with several analytical models taken from the literature and the differences among the models are described through their stiffness matrices.

The analytical model was validated against numerical models developed in SAP2000 and used to perform a parametric analysis in which different wall geometries, anchoring configurations, position of the perpendicular walls and assumptions of the load transfer from the shear wall to the perpendicular walls were considered. The results of the parametric analysis showed that considering the effect of the perpendicular walls increase the lateral stiffness of the shear walls and modifies the contributions of rocking and sliding displacement of the shear walls in comparison to the cases in which the perpendicular walls are not taken into account. It was also shown that stiffening effect of the perpendicular walls strongly depends on the capability of their wall base connections to undertake the uplift and out-of-the-plane forces transferred from the shear walls. With current connection technologies available on the market, the perpendicular walls can contribute to increase up two times the lateral stiffness of shear walls. 
Future studies of the authors will focus on the contribution of the perpendicular walls on the lateral capacity and ductility of the shear walls and on the effects of the box-behaviour at building level.

\section{REFERENCES}

[1] J. Hummel, Displacement-based seismic design for multi-storey cross laminated timber buildings. Dissertation. University of Kassel, 2017.

[2] B. Dujic, S. Aicher, and R. Zarnic, Investigations on in-plane loaded wooden elements - influence of loading and boundary conditions. Otto Graf J., vol. 16, pp. 259-272, 2005.

[3] I. Gavric, M. Fragiacomo, and A. Ceccotti, Cyclic Behavior of CLT Wall Systems: Experimental Tests and Analytical Prediction Models. J. Struct. Eng vol. 141, no. 5, pp. 1-14, 2015.

[4] A. Ceccotti, C. Sandhaas, M. Okabe, M. Yasumura, SOFIE project-3D shaking table test on a seven-storey full-scale cross-laminated building. Earthq. Eng. Struct. Dyn., vol. 13, pp. 2003-2021, October, 2013.

[5] D. Casagrande, S. Rossi, T. Sartori, and R. Tomasi, Proposal of an analytical procedure and a simplified numerical model for elastic response of single-storey timber shearwalls. Constr. Build. Mater., vol. 102, pp. 1101-1112, 2016.

[6] J. W. van de Lindt, S. Pei, S. E. Pryor, H. Shimizu, H. Isoda, Experimental seismic response of a full-scale six-story wood apartment building. 11th World Conf. Timber Eng. 2010, WCTE 2010, vol. 4, October, pp. 3158-3165 2010.

[7] R. Tomasi, T. Sartori, D. Casagrande, and M. Piazza, Shaking table testing of a full-scale prefabricated three-story timber-frame building. J. Earthq. Eng., vol. 19, no. 3, pp. 505534, 2015.

[8] M. Popovski and I. Gavric, Performance of a 2-Story CLT House Subjected to Lateral Loads. J. Struct. Eng., vol. 142, no. 4, pp. 1-12, 2016.

[9] I. Gavric and M. Popovski, Design models for CLT shearwalls and assemblies based on connection properties. Proc. Meet. 47, INTER-Int. Netw. Timber Eng. Res., no. January, pp. 269-280, 2014.

[10] M. Shahnewaz, M. Popovski, and T. Tannert, Deflection of cross-laminated timber shear walls for platform-type construction. Eng. Struct., vol. 221, no. August 2019, p. 111091, 2020.

[11] J. Hummel and W. Seim, Displacement-based design approach to evaluate the behaviour factor for multi-storey CLT buildings. Eng. Struct., vol. 201, December, 2019.

[12] G. Tamagnone, G. Rinaldin, and M. Fragiacomo, A novel method for non-linear design of CLT wall systems. Eng. Struct., vol. 167, no. January 2019.

[13] J. Hummel, W. Seim, and S. Otto, Steifigkeit und Eigenfrequenzen im mehrgeschossigen Holzbau. Bautechnik, vol. 93, no. 11, pp. 781-794, 2016.

[14] M. Wallner-Novak, J. Koppelhuber, and K. Pock, pro:Holz Brettsperrholz Bemessung Grundlagen für Statik und Konstruktion nach Eurocode. 2013.

[15] G. Flatscher, Evaluation and approximatio of timber connection properties for displacement-based analysis of CLT wall systems Dissertation. Graz University of Technology, 2017.

[16] CSI, CSI Analysis Reference Manual. I Berkeley (CA, USA) Comput. Struct. INC, 2013.

[17] I. Gavric, M. Fragiacomo, and A. Ceccotti, Cyclic behavior of typical screwed connections for cross-laminated ( CLT ) structures. European Journal of Wood and Wood Products, vol. 73, pp. 179-191, 2015. 